\title{
The peripheral and central mechanisms underlying itch
}

\author{
Jae Seung Lee , Jasmin Sanghyun Han ${ }^{\#}$, Kyeongho Lee, Juwon Bang E Hyosang Lee \\ Department of Brain and Cognitive Sciences, DGIST, Daegu 42988, Korea
}

\begin{abstract}
Itch is one of the most distressing sensations that substantially impair quality of life. It is a cardinal symptom of many skin diseases and is also caused by a variety of systemic disorders. Unfortunately, currently available itch medications are ineffective in many chronic itch conditions, and they often cause undesirable side effects. To develop novel therapeutic strategies, it is essential to identify primary afferent neurons that selectively respond to itch mediators as well as the central nervous system components that process the sensation of itch and initiate behavioral responses. This review summarizes recent progress in the study of itch, focusing on itch-selective receptors, signaling molecules, neuronal pathways from the primary sensory neurons to the brain, and potential decoding mechanisms based on which itch is distinguished from pain. [BMB Reports 2016; 49(9): 474-487]
\end{abstract}

\section{INTRODUCTION}

Pruritus, or itch, is a sensation that provokes scratching or the desire to scratch (1). Chronic itch is a major distressing symptom associated with many diseases of dermatological, systemic, neurological, or psychogenic origin $(2,3)$. For example, extreme itch is a cardinal symptom of atopic dermatitis, which affects an estimated $17 \%$ of the world's population, primarily infants and children in urban areas and developed countries $(4,5)$. Itch is also a common symptom associated with dry skin in the elderly population, experienced by $30-60 \%$ of the elderly (6). Pruritus often arises as a side effect of medications and therapies, leading many patients to discontinue treatment. For example, $\sim 30 \%$ of African malarial patients refuse to take the anti-malarial drug chloroquine because of unbearable itch $(7,8)$. Chronic itch sufferers frequently cause self-harm through uncontrollable itch-scratch cycles.

*Corresponding author. Tel: +82-53-785-6147; Fax: +82-53-7856109; E-mail: hyosang22@dgist.ac.kr

${ }^{\#}$ These authors contributed equally to this work.

http://dx.doi.org/10.5483/BMBRep.2016.49.9.108

Received 1 July 2016

Keywords: BAM8-22, Chloroquine, Cowhage, Endothelin, Histamine, Itch, MrgprA3, MrgprC11, Primary afferents, Primary sensory neurons, Protease-activated receptor, Pruritogen, Pruritus
Despite the presence of evident clinical significance, our knowledge about etiology and neurobiology of itch is far from complete. In order to develop new and highly selective treatments for a wide variety of persistent itch conditions, we must understand the underlying peripheral and central mechanisms of acute and persistent itch. This review summarizes current knowledge of the molecular and cellular mechanisms underlying itch in the primary afferents and spinal cord and highlights the anatomical structures in the brain that are involved in the sensation and modulation of itch.

\section{PRURICEPTIVE PRIMARY AFFERENTS}

Pruritogens (itch-causing compounds) are produced endogenously, introduced from the environment, or delivered as medications (9-11). They bind to specific receptors expressed in free nerve endings of primary sensory neurons innervating the skin, cornea, and mucous membranes. Activation of itch-specific receptors leads to induction of receptor potentials, which, in turn, are transformed into action potentials in nerve endings. The electrical signals travel alongside the primary sensory neurons to reach the central terminals innervating the dorsal horn of the spinal cord or the trigeminal subnucleus caudalis (VC) (Fig. 1).

In the past decade, significant progress has been made in understanding the peripheral mechanisms of itch. Molecular and mouse genetic approaches have identified itch-sensitive receptors and specific molecular markers that label pruriceptive neurons and also revealed potential drug targets for treating itch. In addition, in vivo extracellular recordings have identified sensory nerve fibers and spinal cord neurons that can be activated by cutaneous pruritogens. Together with human psychophysical studies, these techniques have underscored the strong correlation between neuronal activity and itch sensation.

Itch can be classified into two categories, histaminergic and nonhistaminergic, according to the degree of responsiveness to histamine (9). Histamine, the best-studied itch substance, is a bioactive amine released by mast cells and epithelial cells (12, 13). Intradermal application of histamine produces intense itch, with a flare around the application site $(14,15)$. Histamine binds to specific receptors in the plasma membrane, such as the $\mathrm{H} 1$ and $\mathrm{H} 4$ receptors, leading to the activation of downstream target molecules within sensory neurons, including $\mathrm{G}$ protein, phospholipase $\mathrm{C}$, phospholipase $\mathrm{A}_{2}$,

ISSN: 1976-670X (electronic edition)

Copyright (c) 2016 by the The Korean Society for Biochemistry and Molecular Biology

(ㄷ) This is an open-access article distributed under the terms of the Creative Commons Attribution Non-Commercial License (http://creativecommons.org/licenses/by-nc/4.0) which permits unrestricted non-commercial use, distribution, and reproduction in any medium, provided the original work is properly cited. 

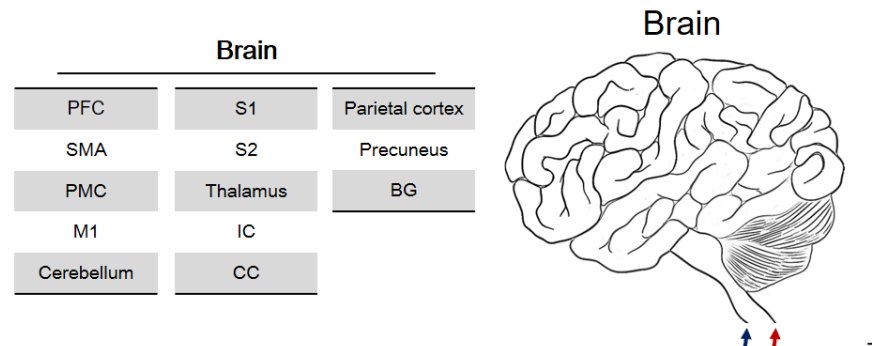

Primary sensory neuron
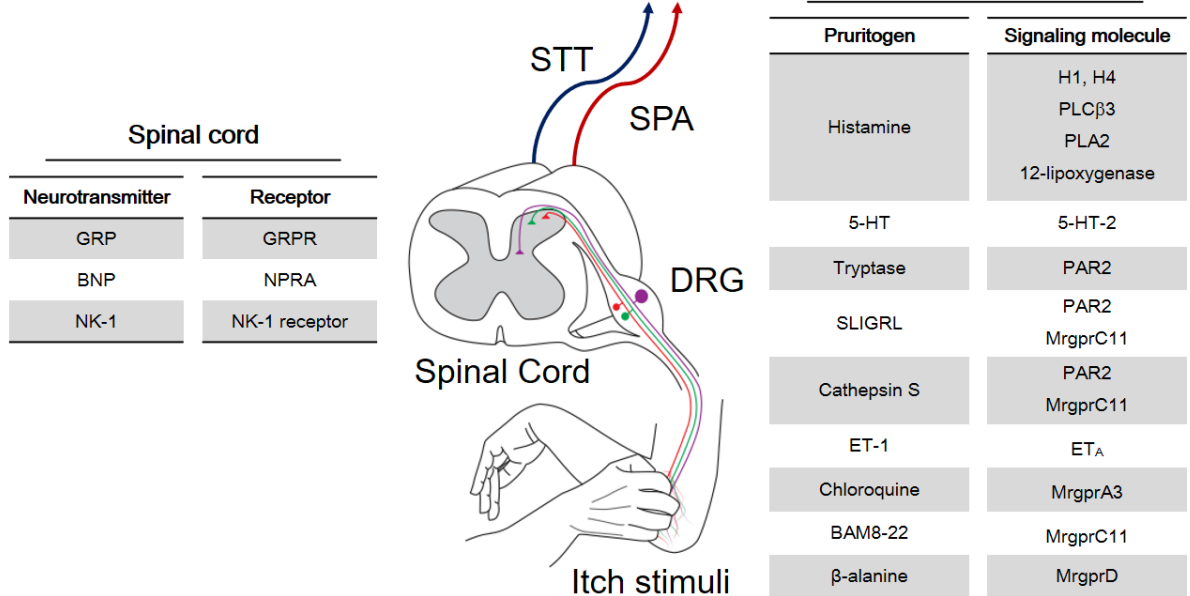

Fig. 1. Itch signaling pathway. Schematic illustrating the transmission of itch from the primary sensory neurons to the brain. Itch stimuli (pruritogens) activate itch-sensing neurons in the dorsal root ganglion (DRG) that innervate the skin, which then stimulate second-order neurons in the spinal cord and multiple brain regions. Indicated in the tables are pruritogens, itch-selective molecules and receptors expressed in the primary sensory neurons and spinal cord, and brain regions activated by cutaneous application of a pruritogen. STT, spinothalamic tract; SPA, spino-parabrachio-amygdaloid pathway; PFC, prefrontal cortex; SMA, supplementary motor area; PMC, premotor cortex; M1, primary motor cortex; S1, primary somatosensory cortex; S2, secondary somatosensory cortex; CC, cingulate cortex; IC, insular cortex; BG, basal ganglia; GRP, gastrin-releasing peptide; GRPR, gastrin-releasing peptide receptor; BNP, B-type natriuretic peptide; NPRA, natriuretic peptide receptor A; NK-1, neurokinin-1; $\mathrm{H} 1$, histamine $\mathrm{H} 1$ receptor; PLC $\beta 3$, phospholipase $\mathrm{C} \beta 3$; PLA2, phospholipase A2; 5-HT, 5-hydroxytryptamine (serotonin); 5-HT-2, 5-HT receptor subtype 2; PAR2, protease-activated receptor 2; Mrgpr, Mas-related G-protein-coupled receptor; $\mathrm{ET}-1$, endothelin-1; $\mathrm{ET}_{\mathrm{A}}$, endothelin-1 receptor $\mathrm{A}$; $\mathrm{BAM} 8-22$, bovine adrenal medullary peptide 8-22.

12-lipoxygenase, and the capsaicin receptor TRPV1 (16-19). It has been shown that phospholipase $\beta 3$ (PLC $\beta 3)$ mediates increase in intracellular calcium level in primary sensory neurons elicited by activation of the histamine $\mathrm{H} 1$ receptor (17). Mice deficient in PLC $\beta 3$ showed a significant defect in scratching behavior elicited by histaminergic pruritogens, including histamine, a selective $\mathrm{H} 1$ agonist histaminetrifluoromethyl toluidine, and the mast cell activator compound 48/80 (17). Histamine-evoked electrophysiological and behavioral responses are substantially reduced by genetic deletion of TRPV1 in mice or by specific inhibitors targeting molecules in the histamine signaling pathway $(18,20-22)$. Mice lacking TRPV1, however, exhibited normal scratching behavior in response to other pruritogens, such as endothelin-1 (ET-1) or 5-HT; whereas, chemical ablation of the central branch of TRPV $1^{+}$neurons leads to a remarkable deficit in scratching in response to those pruritogens as well as histamine, suggesting that TRPV $1^{+}$neurons are able to detect both histaminergic and nonhistaminergic pruritogens $(17,22)$.
In recent years, nonhistaminergic itch has been a main focus of itch research because many chronic itch conditions are not readily alleviated by antihistamine. Cowhage (Mucuna pruriens) is a tropical legume that evokes intense itch as well as pricking, stinging, and burning sensations in humans and scratching in monkeys and mice (23-30). As cowhage-evoked itch is not diminished by antihistamine, it has been the preferred tool for exploring neuronal mechanisms of nonhistaminergic itch. When cowhage spicules are inserted into the skin, the cysteine protease mucunain is released and diffuses to reach nearby nerve endings of primary sensory neurons in the epidermis, thus activating protease-activated receptor (PAR) 2 and $4(23,31,32)$. PARs, members of the G protein-coupled receptor superfamily, are activated by synthetic peptides that match the sequence of the tethered ligands at the receptor's N-terminus, including Ser-Leu-lle-GlyArg-Leu-NH ${ }_{2}$ (SLIGRL) (33). Cutaneous application of SLIGRL elicits scratching behavior in animals (34). PAR2 and tryptase, the endogenous PAR2 agonist, are markedly increased in the 
skin of atopic dermatitis patients (35).

A large family of sensory neuron-specific $G$ protein-coupled receptors known as Mas-related $\mathrm{G}$ protein-coupled receptors (Mrgprs) plays a key role in detecting nonhistaminergic pruritogens (36). MrgprA3 is expressed in a tiny subset of sensory neurons (4-5\%) classified as peptidergic C-fibers (37). It has been identified as a receptor for a pruritic antimalarial medication, chloroquine, which evokes intense itch in humans, particularly those of African descent $(7,38)$. In vivo extracellular recordings reveal that MrgprA $3^{+}$neurons are not only sensitive to chloroquine but also to histamine, bovine adrenal medulla 8-22 (BAM8-22), cowhage spicules, and even the pungent vanilloid compound capsaicin. BAM8-22, a proteolytic cleavage product of proenkephalin A, provokes itch in humans, usually accompanied by pricking, stinging, and burning sensations $(39,40)$. Mice ablated of MrgprA3 ${ }^{+}$ neurons exhibited a substantial deficit in scratching behavior evoked by diverse pruritogens, such as histamine, BAM8-22, SLIGRL, $\alpha$-methyl-5HT, ET-1, as well as chloroquine (38). However, in ablated mice, normal response to $\beta$-alanine, a supplement for muscle building that causes itch sensations in humans and scratching behavior in mice was noted (41). These findings suggest that $\mathrm{MrgrpA}^{+}$sensory neurons are able to detect diverse pruritogens, and a different population of neurons mediates $\beta$-alanine-evoked itch.

In fact, MrgprA3 is highly co-expressed with another Mrgpr, MrgprC11, which has been identified as a receptor for pruritic peptides such as BAM8-22, SLIGRL, and the cysteine protease, cathepsin S (38, 42, 43). Mice lacking a cluster of Mrgprs, including MrgprC11, exhibit a substantial deficit in scratching behavior to these pruritogens, but their response to other pruritogens, such as histamine and compound 48/80, remains normal $(38,42-44)$. Since mice lacking PAR2 exhibit a normal response to subcutaneously injected SLIGRL, MrgprC11 is contemplated to be a major contributor to SLIGRL-evoked itch (42).

MrgprD has been identified as a receptor that is specifically activated by $\beta$-alanine (45), and mice lacking MrgprD fail to exhibit scratching after intradermal injection of $\beta$-alanine (41). Since MrgprA3 and MrgprD are expressed in distinct subpopulations of $\mathrm{C}$-fibers in mice, $\mathrm{MrgprA}^{+}$neurons are unresponsive to $\beta$-alanine in in vivo extracellular recordings, and mice ablated of $\mathrm{MrgprA3}^{+}$neurons are normal in response to $\beta$-alanine, these receptors are apparently expressed in two distinct populations of pruriceptive neurons $(46,47)$.

It has been reported that TRPA1 is one of the key players in Mrgpr-mediated itch (48). For example, chloroquine and BAM8-22 activate a subset of TRPA1-expressing sensory neurons. Cultured sensory neurons isolated from TRPA1deficient mice exhibit a remarkable reduction in calcium responses evoked by chloroquine and BAM8-22, but their histamine-evoked responses are unaffected. Conversely, sensory neurons from TRPV1-deficient mice respond normally to chloroquine and BAM8-22, but their histamine-evoked responses are substantially reduced. Thus, TRPV 1 and TRPA 1 are recruited to serve different types of itch, even though TRPA $^{+}$cells are known to express TRPV1 (49). Mice lacking TRPA1 exhibit almost no scratching behavior upon subcutaneous injection of chloroquine and BAM8-22, but they show normal scratching in response to $\alpha$-methyl-5HT, indicating that their deficit is specific to certain pruritogens.

ET-1, a potent vasoconstriction peptide, is produced by mast cells, endothelial cells, and keratinocytes $(50,51)$. ET-1 elicits the sensation of itch accompanied by flare reactions in humans and scratching in mice (52-54). A monoamine neurotransmitter, $5-\mathrm{HT}$, also causes itch by activating the 5-HT-2 receptor after cutaneous application (55-58).

It is likely that itch is mediated by several different subpopulations of primary sensory neurons. Some itch-causing substances activate mostly overlapping populations of neurons, since their specific receptors are expressed in the same neurons (e.g., chloroquine vs. BAM8-22; MrgprA3 vs. MrgprC11), and other pruritogens activate distinct populations (e.g., chloroquine vs. $\beta$-alanine; MrgprA3 vs. MrgprD). The number of itch-responding sensory neurons and extent of overlap between responding populations are variable, depending on the type of pruritogen, method of delivery, and species.

A substantial body of evidence indicates that the vast majority of pruritogen-sensitive sensory neurons respond not only to pruritogens but also to noxious mechanical, thermal, and/or chemical stimuli $(27,57,59-61)$. In human microneurography, for example, intradermal injection of histamine preferentially activates a subset of mechanically insensitive C-fibers (C-MIA) over a time-course matching the psychophysical sensation of itch, whereas topical application of cowhage spicules activates a subset of mechano-heat-sensitive C-fibers (CMH) $(26,27,62-64)$. Most itch-sensitive C-MIAs and CMHs are also activated by intradermal injection of capsaicin. Thus, histamine and cowhage activate two distinct subpopulations of primary sensory neurons, which also respond to noxious stimuli in humans. In nonhuman primates, however, both histamine and cowhage activate a subset of $\mathrm{CMHs}$ that also respond to noxious stimuli, indicating activation of overlapping population of neurons (also respond to noxious stimuli) by pruritogens (27). In line with this finding, native cowhage spicules and heat-inactivated spicules containing histamine applied to the mouse skin activate a subset of $\mathrm{CMH}$; over $60 \%$ of histamine-sensitive $\mathrm{CMH}$ also respond to cowhage (30). Conversely, half of the cowhage-responsive fibers are also activated by histamine. For the reason that these histamine- and cowhage-sensitive neurons also respond to noxious stimuli, they represent partially overlapping subpopulations of nociceptors. Other studies have also shown that diverse pruritogens activate partially overlapping subpopulations of nociceptors in rodent trigeminal and dorsal root ganglia (38, $54,65-67)$. 


\section{PRURICEPTIVE NEURONS IN THE SPINAL CORD AND SPINAL TRIGEMINAL NUCLEUS}

Itch-sensitive primary sensory neurons release specific neurotransmitters onto postsynaptic neurons in the spinal cord and $\mathrm{V}_{\mathrm{c}}$, where the itch signal is further processed by local excitatory and inhibitory neurons as well as descending synaptic inputs from the brain, before the itch information is transmitted to supraspinal regions, such as the thalamus and parabrachial nucleus (PB), via ascending neuronal pathways (Fig. 1). Projection neurons comprise only a small fraction of the neurons in the dorsal horn ( $\sim 5 \%$ of lamina I neurons in the $\mathrm{L} 4$ segment of the rat spinal cord), and many of them send collateral projections to synapse with multiple brain regions (68).

In conjunction with glutamate and substance $\mathrm{P}$, gastrinreleasing peptide (GRP) has been considered as a key neuropeptide transmitter that is released from either the central terminals of itch-sensitive primary sensory neurons or local excitatory neurons, activating dorsal horn neurons that express the GRP receptor (GRPR) $(11,69-72)$. GRP is a homolog of bombesin, a 14-amino acid peptide originally isolated from frog skin; intrathecal or intradermal injection of bombesin provokes scratching in animals (71, 73-76). Mice lacking GRPR or ablated of $\mathrm{GRPR}^{+}$neurons display a substantial reduction in scratching behavior in response to a variety of pruritogens, such as compound 48/80, SLIGRL, and chloroquine, but normal responses to painful stimuli, indicating that GRPR ${ }^{+}$neurons are selectively involved in itch signaling $(69,76)$. Consistent with this finding, mice deficient in the testicular orphan nuclear receptor exhibit a near-complete absence of scratching behavior in response to histamine, $\alpha-\mathrm{Me}-5-\mathrm{HT}$, and chloroquine (77). In these mice, $\sim 80 \%$ of $\mathrm{GRP}^{+}$or $\mathrm{GRPR}^{+}$neurons are ablated, suggesting the importance of GRP signaling in itch responses (77).

B-type natriuretic peptide (BNP, also known as natriuretic polypeptide B) is another itch-specific neurotransmitter expressed in a subset of primary sensory neurons that co-express MrgprA3, TRPV1, and PLCB3 (71). It is released from the central terminals of these neurons to activate the postsynaptic second-order neurons in the spinal cord. Mice lacking in BNP exhibit greatly attenuated responses to a range of pruritic agents but retain normal reactions to thermal, touch, and proprioceptive stimuli. Conversely, intrathecal injection of BNP induces robust scratching in mice. Consistent with these findings, ablation of spinal interneurons expressing NPRA, a receptor for BNP, leads to a major attenuation in itch responses to intradermal injection of histamine or intrathecal administration of $\mathrm{BNP}$, but normal reactions to other somatosensory stimuli. Thus, BNP signaling plays a key role in itch transmission. It has been proposed that $\mathrm{NPRA}^{+}$neurons are the elements upstream of $\mathrm{GRPR}^{+}$neurons in itchtransmitting circuits (71).

In order to determine the neural basis of itch processing in the spinal cord, in vivo single-unit recordings have been performed from the spinal cord and $\mathrm{V}_{\mathrm{c}}$, following application of itch stimuli to the skin. The dorsal horn neurons can be classified according to their responsiveness to mechanoinsensitive and noxious mechanical stimuli, into: 1) mechanoinsensitive (MI), 2) low-threshold, 3) wide dynamic range (WDR), and 4) nociceptive-specific (NS) neurons (11, 78-80). WDR neurons respond to both innocuous and noxious mechanical stimuli, with higher-frequency discharges in response to noxious stimuli.

In vivo recordings have shown that the vast majority of itch-sensitive neurons in the spinal cord and $V_{c}$ are WDR and NS neurons, and only a few are MI neurons. Most of these neurons are nociceptors that also respond to noxious stimuli. For example, in nonhuman primates, histamine and cowhage activate two mostly separate subpopulations of neurons in the spinal cord, all of which are either WDR or NS neurons that also respond to noxious mechanical or thermal stimuli, indicating that histaminergic and nonhistaminergic itch are carried by two separate subpopulations responding to nociceptive stimuli $(60,61,81)$. Antidromic mapping has revealed that the neurons involved are the spinothalamic tract (STT) neurons projecting into the ventrobasal and posterior nucleus of the thalamus. Similarly, in rodents, the dorsal horn of the spinal cord and $V_{C}$ contain a number of pruritogen-sensitive neurons, mostly WDR and NS neurons that also respond to noxious stimuli $(11,54,57,65,82,83)$. These findings also support the concept that itch information is mediated in the spinal cord and $V_{c}$ by a subset of nociceptive neurons responding to noxious stimuli. Only a small fraction of itch-sensitive neurons are MI. Previous research in cats has identified a small number of histamine-sensitive Ml neurons from the STT (84). Half of all histamine-sensitive neurons are unresponsive to the noxious chemical mustard oil, indicating the existence of itch-specific neurons that are insensitive to noxious mechanical or chemical stimuli. However, the response of $\mathrm{CMHs}$ was not examined in the reported study.

It is likely that the vast majority of pruritogen-responsive neurons are local interneurons, since only a small subset of pruriceptive neurons in the spinal cord and $\mathrm{V}_{\mathrm{c}}$ are projection neurons that innervate either the thalamus or PB in mice (85).

\section{NEURAL CODING MECHANISMS OF ITCH AND PAIN}

Itch is closely linked to pain, and electrophysiological studies have shown that the majority of itch-sensitive neurons are nociceptors, thus raising an important question as how itch is differentiated from pain. Both itch and pain are complex sensory and emotional experiences created by neuronal activities in the peripheral and central nervous systems. They are detected by a subset of primary afferents in the somatosensory system, mainly by slowly conducting unmyelinated C-fibers and thinly myelinated A $\delta$-fibers (9, 29, $86)$. The similar sets of receptors and signaling molecules are 
involved in transducing itch and pain within sensory neurons. As such, pruriceptive and noxious stimuli often activate the shared populations of neurons. Moreover, alleviation of pain can produce a sensation of itch; morphine, for example, inhibits pain but causes a sensation of itch in humans and scratching behavior in animals (87-89). Conversely, itch is temporarily relieved by scratching. Finally, it is apparent that both itch and pain elicit unpleasant sensations. However, they clearly evoke qualitatively different sensations and behavioral responses, suggesting that there should be a mechanism based on which itch and pain can be differentiated.

There have been debates on the neural basis of itch processing. For many years, itch has been considered as a sub-modality of pain in which itch and pain are served by the same population of neurons, and the sensation is determined by the pattern of neuronal activity; itch is elicited when sensory neurons are activated weakly, whereas pain is evoked when neurons are strongly activated (9). This so-called intensity theory was supported by the experimental finding that most of the itch-sensitive neurons also respond to painful stimuli. Moreover, high doses of pruritogen produce pain, whereas low doses of algogen evoke itch. For instance, intradermal injection of a high concentration of histamine elicits pain $(90,91)$. Conversely, capsaicin, which normally causes intense burning pain when injected intradermally, elicits itch when delivered topically or applied as heatinactivated cowhage spicules coated with capsaicin (28, 91-95).

Primary afferents and postsynaptic neurons in the spinal cord exhibit relatively higher-frequency discharges in response to noxious stimuli than do pruritogens $(30,54,60,61,65$, 81-83, 96). For example, capsaicin provokes higher-frequency discharges in the trigeminothalamic and STT neurons as compared to histamine or cowhage $(30,60,81,96)$. The manner in which information contained in the pattern of activity is used to produce specific sensation of itch in higher-order neurons in the brain remains to be determined. There exists experimental evidence that challenges the intensity theory. For instance, an itch sensation provoked by neuronal or cutaneous electrical stimulation does not transform into pain at higher-frequency stimulation $(97,98)$. Also, a specific firing pattern of $\mathrm{CMH}$ s does not correlate with itch and pain sensation in humans (99). Since these studies have focused on primary afferents, it remains unclear whether intensity coding is a valid mechanism in the spinal cord and brain.

A number of pieces of genetic and behavioral evidence support another theory, the "labeled line" theory, in which specific populations of neurons are dedicated to serving either itch or pain. For example, mice ablated of either MrgprA3 ${ }^{+}$ primary sensory neurons, $\mathrm{GRPR}^{+}$neurons in the spinal cord, or NPRA ${ }^{+}$neurons in the spinal cord, or mice lacking BNP all exhibit a selective deficit in scratching behavior in response to a variety of pruritogens, whereas these manipulations have no effect on nociception $(37,69,71)$. In an elegant genetic experiment, TRPV1-knockout mice were engineered to express TRPV1 only in itch-sensitive MrgprA3 $^{+}$primary sensory neurons (37). When capsaicin was applied, these animals exhibited only itch-related behaviors without pain-related behaviors; even though $\mathrm{MrgprA3}^{+}$neurons were found to respond to noxious stimuli in electrophysiological recordings. To accommodate the discrepancies in the electrophysiological and behavioral findings, a new theory, known as "population coding" was proposed, in which the sensation of itch is elicited by activating "pruriceptive nociceptors" that respond to both pruriceptive and noxious stimuli in electrophysiological recordings; in contrast, the sensation of pain is elicited by noxious stimuli, which activate an additional population responding only to noxious stimuli $(9,11)$. The activity in the "nociceptive-specific" population is speculated to prevent or mask itch transmission by the pruriceptive nociceptors, possibly via local inhibitory mechanisms.

Several lines of evidence support this model. First, selective deletion of vesicular glutamate transporter 2 in a subset of nociceptive neurons leads to spontaneous scratching and capsaicin-evoked itch in mice, suggesting that baseline glutamatergic signaling inhibits itch transmission $(100,101)$. Second, activity-dependent silencing of a subset of nociceptors using the lidocaine derivative QX-314, followed by activation of another subpopulation of nociceptors, elicits scratching rather than pain behavior in mice (102). QX-314 permeates through activated ion channels such as TRPV1 and inhibits neuronal firing by blocking voltage-gated channels inside the cell. Finally, selective ablation of inhibitory interneurons expressing the transcription factor basic helix-loop-helix domain-containing, class B5 (BHLHB5) results in a substantial elevation of spontaneous scratching, suggesting a potential role for these neurons in suppressing itch transmission by pruriceptive nociceptors (103). A recent study has shown that transplantation of precursors of cortical inhibitory neurons in the spinal cord can rescue the itch-related phenotypes of these mice, presumably by restoring inhibitory mechanisms in the spinal cord (104). The local circuit involving BHLHB5 neurons remains to be determined.

\section{ITCH PROCESSING IN THE BRAIN}

One of the major insights that has emerged from pain studies is that chronic pain is a disease not only of the primary sensory neurons and spinal cord but also of the brain. Chronic pain causes functional and structural alterations in the brain and also affects other functions of brain such as emotion, motivation, and memory. Therefore, developing an effective itch treatment must take into consideration a therapeutic strategy targeting the brain.

Itch is a multidimensional experience that involves perception of the sensory and emotional-affective aspects of itch as well as an urge to scratch employing the motor system (1). 
Table 1. Brain activity upon itch stimulation

\begin{tabular}{|c|c|c|c|c|c|}
\hline Subject & Imaging & Stimulus (method) & Location & Brain region & Reference \\
\hline Healthy & PET & $\begin{array}{l}\text { Histamine } \\
\text { (Intracutaneous } \\
\text { injection) }\end{array}$ & Right forearm & $\begin{array}{l}\text { SFG(bi), MFG(bi), IFG(R), SMA(bi), PMC(bi), ACC(L), IPL(R), } \\
\text { Cerebellum(bi) }\end{array}$ & ref. 125 \\
\hline Healthy & PET & Histamine (skin prick) & Right forearm & $\operatorname{PFC}(\mathrm{L}), \mathrm{SMA}(\mathrm{L}), \mathrm{PMC}(\mathrm{L}), \mathrm{M1}(\mathrm{L}), \mathrm{S} 1(\mathrm{~L}), \mathrm{PC}(\mathrm{SMG}(\mathrm{L}))$ & ref. 126 \\
\hline Healthy & PET & Histamine (skin prick) & Right forearm & $\begin{array}{l}\mathrm{PFC}(\mathrm{L}) \text {, preCG(L), IFG(L), MFG(L) SMA(L), PMC(L), ACC }(\mathrm{L}) \text {, } \\
\text { PC (postcentral(R) \& superior }(\mathrm{R}))\end{array}$ & ref. 105 \\
\hline Healthy & fMRI & Histamine (skin prick) & Right foot & $\begin{array}{l}\text { periACC(bi), alC(bi), plC(L), BG (caudate(bi), ventral caudate(R), } \\
\text { ventral putamen }(\mathrm{R})), \mathrm{TH}(\mathrm{bi})\end{array}$ & ref. 112 \\
\hline Healthy & fMRI & Histamine (skin prick) & Left forearm & IFG(R), IC(R), preCG(L) $\downarrow$, MFG $\downarrow$, preACC $\downarrow$, subACC $\downarrow$, cerebellum $\downarrow$ & ref. 137 \\
\hline Healthy & fMRI & $\begin{array}{l}\text { Histamine (skin prick) } \\
\text { at } 25^{\circ} \mathrm{C} \text { (skin) }\end{array}$ & Right forearm & $\begin{array}{l}\text { dlPFC(bi), preSMA(R), alC(L), iPC(bi), TH(bi), OFC(L) } \downarrow, \operatorname{MFC}(R) \downarrow \\
\text { M1(L) } \downarrow, \text { dACC(R) } \downarrow\end{array}$ & ref. 148 \\
\hline Healthy & PET & $\begin{array}{l}\text { Histamine } \\
\text { (iontophoresis) }\end{array}$ & Right foot & dIPFC(bi), PMC(R), CC(L), aPC(R), pPC(R), TH(L) & ref. 110 \\
\hline Healthy & fMRI & $\begin{array}{l}\text { Histamine } \\
\text { (iontophoresis) }\end{array}$ & Left wrist & $\operatorname{preSMA}(\mathrm{L}), \mathrm{ACC}(\mathrm{R}), \mathrm{PCC}(\mathrm{R}), \mathrm{alC}(\mathrm{bi}), \mathrm{plC}(\mathrm{L}), \mathrm{BG}(\mathrm{L})$ & ref. 107 \\
\hline Healthy & PET & he & Left hand & $\operatorname{SFG}(\mathrm{L})$, $\operatorname{preCG}(\mathrm{R})$, postCG $(\mathrm{R}), \mathrm{MCG}(\mathrm{R})$ & ref. 127 \\
\hline Healthy & fMRI & $\begin{array}{l}\text { Histamine } \\
\text { (iontophoresis) }\end{array}$ & Right forearm & M1(L), S1(L), precuneus $(\mathrm{L}), \operatorname{IPL}(\mathrm{L}), \mathrm{SPL}(\mathrm{L})$ & ref. 124 \\
\hline Healthy & fMRI & $\begin{array}{l}\text { Histamine } \\
\text { (microdialysis) }\end{array}$ & Left forearm & $\begin{array}{l}\text { SFG(R), MFG(bi), IFG(L), preCG(bi), SMA(bi), PMC(bi), S1(R), S2(bi), } \\
\text { aMCC(bi), precuneus(R), IPL(bi), SPL(R), alC(bi), BG (caudate body(bi), } \\
\text { caudate tail(bi)), TH(bi), cerebellum, subACC(bi) } \downarrow \text {, amygdala(bi) } \downarrow\end{array}$ & ref. 106 \\
\hline Healthy & fMRI & Cowhage & Right forearm & $\begin{array}{l}\mathrm{PMC}(\mathrm{L}), \mathrm{S} 1(\mathrm{~L}), \mathrm{S} 2(\mathrm{bi}), \mathrm{PCC}(\mathrm{bi}), \mathrm{ACC}(\mathrm{L}) \text {, precuneus }(\mathrm{L}), \mathrm{IC}(\mathrm{bi}), \mathrm{SMG}(\mathrm{bi}) \text {, } \\
\text { angular gyrus(bi), hippocampus(L), putamen(bi), TH(bi), cerebellum(L) }\end{array}$ & ref. 113 \\
\hline Healthy & fMRI & $\begin{array}{l}\text { Histamine } \\
\text { (iontophoresis) \& } \\
\text { cowhage }\end{array}$ & Right forearm & $\begin{array}{l}\mathrm{SFG}(\mathrm{R}), \mathrm{OFC}(\mathrm{L}), \operatorname{IFG}(\mathrm{R}), \mathrm{SMG}(\mathrm{L}), \mathrm{S} 1(\mathrm{~L}), \mathrm{S} 2(\mathrm{R}), \mathrm{ACC}(\mathrm{bi}), \mathrm{PCC}(\mathrm{bi}), \mathrm{IC}(\mathrm{bi}) \text {, } \\
\text { angular gyrus(L), } \operatorname{IPL}(\mathrm{L}), \mathrm{SPL}(\mathrm{L}), \text { precuneus(bi), BG (putamen(bi), } \\
\text { lateral globus pallidus(L)), Amygdala(bi), } \mathrm{TH}(\mathrm{L})\end{array}$ & ref. 113 \\
\hline Healthy & fMRI & Allergen (skin prick) & Right foot & $\begin{array}{l}\text { mOFC(L), middle OFC(L), IOFC(L), SMA(L), PMC(L), M1(L), S1(L), } \\
\text { periACC, subACC(bi), pPC(L), BG (caudate(bi)), TH(R) }\end{array}$ & ref. 112 \\
\hline Healthy & fMRI & Electrical stimulus & Left wrist & $\begin{array}{l}\operatorname{PFC}(\mathrm{R}), \mathrm{SMA}(\mathrm{R}), \mathrm{PMC}(\mathrm{R}), \mathrm{S} 2(\mathrm{bi}), \mathrm{ACC}(\mathrm{L}), \mathrm{PCC}(\mathrm{L}) \text {, precuneus }(\mathrm{R}), \mathrm{IC}(\mathrm{bi}) \text {, } \\
\text { aPC(bi), } \mathrm{pPC}(\mathrm{R}), \mathrm{TH} \text {, cerebellum }(\mathrm{L})\end{array}$ & ref. 111 \\
\hline $\begin{array}{l}\mathrm{AD} \text { (no active } \\
\text { phase) }\end{array}$ & PET & $\begin{array}{l}\text { Histamine } \\
\text { (iontophoresis) }\end{array}$ & Left hand & $\begin{array}{l}\text { SFG(bi), MFG(R), IFG(bi), preCG(bi), postCG(R), IC(L), PC (SMG }(\mathrm{R})) \text {, } \\
\text { BG (pallidum(L)), TH(R), cerebellum(bi) }\end{array}$ & ref. 127 \\
\hline $\mathrm{AD}$ & $\mathrm{fMRI}$ & $\begin{array}{l}\text { Histamine } \\
\text { (iontophoresis) }\end{array}$ & $\begin{array}{l}\text { Right forearm } \\
\text { (LS) }\end{array}$ & $\begin{array}{l}\text { dIPFC(bi), IPFG(L), SFG(bi), MFG(R), IFG(L), PMC(bi), vACC(bi), } \\
\text { dACC(bi), vPCC(bi), dPCC(bi), RSC(bi), precuneus(bi), alC(R), pIC(R), } \\
\text { IPL(R), SPL(R), BG (caudate(L), putamen(L)) }\end{array}$ & ref. 124 \\
\hline AD & fMRI & $\begin{array}{l}\text { Histamine (skin prick) } \\
\text { at } 25^{\circ} \mathrm{C} \text { (skin) }\end{array}$ & $\begin{array}{l}\text { Right forearm } \\
\text { (NLS) }\end{array}$ & $\mathrm{PFC} \downarrow, \mathrm{SMA} \downarrow, \mathrm{PMC} \downarrow, \mathrm{S} 1 \downarrow, \mathrm{S} 2 \downarrow, \mathrm{CC} \downarrow, \mathrm{IC} \downarrow, \mathrm{BG} \downarrow$ & ref. 149 \\
\hline AD & fMRI & $\begin{array}{l}\text { Histamine (skin prick) } \\
\text { at } 25^{\circ} \mathrm{C} \text { (skin) }\end{array}$ & $\begin{array}{l}\text { Right forearm } \\
\text { (LS) }\end{array}$ & 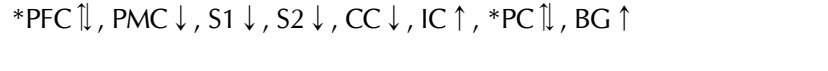 & ref. 149 \\
\hline ESRD & fMRI & $\begin{array}{l}\text { Histamine } \\
\text { (iontophoresis) }\end{array}$ & Right forearm & $\begin{array}{l}\mathrm{OFC}(\mathrm{L}), \mathrm{SFG}(\mathrm{R}), \mathrm{MFG}(\mathrm{R}), \mathrm{IFG}(\mathrm{L}), \mathrm{S} 1(\mathrm{~L}), \mathrm{ACC}(\mathrm{L}), \mathrm{PCC}(\mathrm{bi}) \text {, paracingulate } \\
\text { gyrus }(\mathrm{L}) \text {, precuneus }(\mathrm{bi}), \mathrm{SPL}(\mathrm{bi}), \mathrm{SMG}(\mathrm{L}) \text {, angular gyrus }(\mathrm{L})\end{array}$ & ref. 114 \\
\hline ESRD & fMRI & Cowhage & Right forearm & $\begin{array}{l}\mathrm{PMC}(\mathrm{bi}), \mathrm{M} 1(\mathrm{R}), \mathrm{S} 1(\mathrm{~L}), \mathrm{S} 2(\mathrm{~L}), \mathrm{ACC}(\mathrm{bi}), \mathrm{PCC}(\mathrm{R}) \text {, precuneus(bi), IC(L), } \\
\text { angular gyrus(L), SMG(L), BG (putamen }(\mathrm{L})), \mathrm{TH}(\mathrm{R})\end{array}$ & ref. 114 \\
\hline
\end{tabular}

Brain imaging studies have shown that cutaneous application of pruritogens (cowhage and histamine) or electrical stimulation lead to activity changes in multiple brain regions of healthy subjects and chronic itch patients $(R$, right hemisphere; $L$, left hemisphere; bi, both hemispheres). Unless otherwise indicated with $(\downarrow)$, all regions were activated during pruritic stimulation. ${ }^{*}$ Mixed activity (both activation and deactivation) was found within a region. PFC, prefrontal cortex; dIPFC, dorsolateral prefrontal cortex; OFC, orbitofrontal cortex; mOFC, medial orbitofrontal cortex; middleOFC, middle orbitofrontal cortex; IOFC, lateral orbitofrontal cortex; MFC, medial frontal cortex; SFG, superior frontal gyrus; MFG, middle frontal gyrus; IFG, inferior frontal gyrus; iPFG, inferior prefrontal gyrus; preCG, precentral gyrus; postCG, postcentral gyrus; SMA, supplementary motor area; preSMA, presupplementary motor area; PMC, premotor cortex; M1, primary motor cortex; S1, primary somatosensory cortex; S2, secondary somatosensory cortex; CC, cingulate cortex; ACC, anterior cingulate cortex; $\mathrm{dACC}$, dorsal anterior cingulate cortex; vACC, ventral anterior cingulate cortex; preACC, pregenual anterior cingulate cortex; periACC, perigenual anterior cingulate cortex; subACC, subgenual anterior cingulate cortex; aMCC, anterior midcingulate cortex; MCG, midcingulate gyrus; PCC, posterior cingulate cortex; dPCC, dorsal posterior cingulate cortex; VPCC, ventral posterior cingulate cortex; RSC, restrosplenial cingulate cortex; PC, parietal cortex; aPC, anterior parietal cortex; pPC, posterior parietal cortex; iPC, inferior parietal cortex; SMG, supramarginal gyrus; IPL, inferior parietal lobe; SPL, superior parietal lobe; IC, insular cortex; alC, anterior insular cortex; plC, posterior insular cortex; $\mathrm{BG}$, basal ganglia; $\mathrm{TH}$, thalamus; $\mathrm{AD}$, atopic dermatitis; $\mathrm{ESRD}$, end-stage renal disease; $\mathrm{LS}$, lesional skin; NLS, nonlesional skin. 
The perception of itch occurs in the brain by interpreting the neuronal activities stemming from projection neurons in the spinal cord and $V_{c}$ that receive itch signals from pruriceptive primary afferents.

Our current knowledge on itch processing in the brain is derived from a small number of brain imaging studies performed on human subjects, which have utilized techniques such as positron emission tomography, functional magnetic resonance imaging, and magnetoencephalography. Itch was produced in healthy subjects by histamine, cowhage, or electrical stimulus delivered locally to the skin, leading to increased or decreased cerebral activity as well as the sensation of itch (Table 1). A few studies focused on itch processing in the brain of chronic itch patients suffering from atopic dermatitis or end-stage renal disease (ESRD), and other studies tested cerebral activity during suppression of itch (Table 2).
As mentioned above, itch-mediating projection neurons in the spinal cord and $V_{c}$ are a small subset of WDR and NS neurons that also respond to noxious stimuli. Thus, it is highly likely that itch and pain share common neuronal pathways to and within the brain. Consistent with this idea, brain regions activated by pruritic and noxious stimuli overlap extensively (105-107). Pruriceptive STT neurons send their axons across the midline of the spinal cord and ascend within the anterolateral column pathway to reach the contralateral thalamus, particularly within the ventroposterior medial or posterior thalamic nuclei $(60,61,81,84,108)$. As is true for pain, itch information may be further relayed to the primary (S1) and secondary (S2) somatosensory cortices, insular cortex (IC), and cingulate cortex $(108,109)$. Multiple studies have demonstrated thalamus as one of the prominent regions, which is consistently activated by histamine and cowhage (106, 110-113). Interestingly, cowhage elicits more extensive

Table 2. Brain activity during itch suppression

\begin{tabular}{|c|c|c|c|c|c|}
\hline Subject & Imaging & Itch (suppression) & Location & Brain region & Reference \\
\hline Healthy & PET & $\begin{array}{l}\text { Histamine - iontophoresis } \\
\quad\left(\text { Cold pain }\left(5^{\circ} \mathrm{C}\right)\right)\end{array}$ & $\begin{array}{l}\text { Right foot (itch) } \\
\text { Left foot (pain) }\end{array}$ & S2(bi), TH(R), Midbrain(R) (including PAG) & ref. 110 \\
\hline Healthy & fMRI & $\begin{array}{l}\text { Histamine - iontophoresis } \\
\text { (Passive scratching) }\end{array}$ & Right hand & $\begin{array}{l}\text { MFC(bi), LFC(bi), PMC(bi), M1(bi), S1(bi), S2(bi), } \\
\text { subACC(bi), preACC(bi), dPCC(bi), vPCC(bi), alC(bi), } \\
\operatorname{plC(bi),~PC(bi),~BG~(putamen(bi)),~TH(bi),~cerebellum(bi)~}\end{array}$ & ref. 128 \\
\hline Healthy & fMRI & $\begin{array}{l}\text { Cowhage i } \\
\text { (Passive scratching) }\end{array}$ & Right forearm & $\begin{array}{l}\text { S1, S2, PCC, precuneus, hippocampus, subthalamic } \\
\text { nucleus, vIPFC } \downarrow, \text { OFC } \downarrow, \text { M } 1 \downarrow, \text { ACC } \downarrow, I C \downarrow, T H \downarrow \text {, } \\
\text { BG (Putamen) } \downarrow\end{array}$ & ref. 129 \\
\hline Healthy & fMRI & $\begin{array}{l}\text { Cowhage } \\
\text { (Active scratching) }\end{array}$ & Right forearm & $\begin{array}{l}\text { dIPFC, SMA, PMC, M1, S1, S2, ACC, PCC, precuneus, } \\
\text { BG (Caudate), TH, cerebellum, vIPFC } \downarrow \text {, OFC } \downarrow \text {, frontal } \\
\text { medial cortex } \downarrow \text {, ACC } \downarrow, \text { IC } \downarrow \text {, NAC } \downarrow \text {, hippocampus } \downarrow \text {, } \\
\text { amygdala } \downarrow \text {, cerebellum (anterior lobe, culmen) } \downarrow \text {, } \\
\text { midbrain (VTA, PAG, Dorsal nucleus of the raphé) } \downarrow\end{array}$ & ref. 129 \\
\hline Healthy & fMRI & $\begin{array}{l}\text { Cowhage } \\
\text { (Active scratching) }\end{array}$ & Right forearm & $\begin{array}{l}\operatorname{dmPFC}(R), \operatorname{IPFC}(b i), P M C(R), M 1(b i), S 1(b i), A C C(R) \\
\text { MCC(bi), IC(bi), PC(bi), TH(bi), cerebellum(bi) }\end{array}$ & ref. 130 \\
\hline Healthy & fMRI & $\begin{array}{l}\text { Histamine - iontophoresis } \\
\text { (Butorphanol) }\end{array}$ & Right forearm & $\operatorname{subACC}(R)$ & ref. 150 \\
\hline Healthy & fMRI & Cowhage (Butorphanol) & Right forearm & $\begin{array}{l}\mathrm{S} 1(\mathrm{~L}) \downarrow, \mathrm{PCC}(\mathrm{L}) \downarrow, \mathrm{IC}(\mathrm{R}) \downarrow, \mathrm{TH}(\mathrm{L}) \downarrow, \\
\quad \text { cerebellum (culmen }(\mathrm{L})) \downarrow\end{array}$ & ref. 150 \\
\hline $\begin{array}{l}\text { AD, psoriasis, } \\
\text { ESRD }\end{array}$ & fMRI & $\begin{array}{l}\text { Cowhage } \\
\text { (Active scratching) }\end{array}$ & Right forearm & $\begin{array}{l}\operatorname{dmPFC}(\mathrm{L}), \operatorname{vmPFC}(\mathrm{L}), \operatorname{IPFC}(\mathrm{bi}), \mathrm{SMA}, \mathrm{PMC}(\mathrm{bi}), \mathrm{M} 1(\mathrm{~L}), \mathrm{S} 1(\mathrm{~L}), \\
\mathrm{ACC}(\mathrm{R}), \operatorname{MCC}(\mathrm{R}), \text { precuneus }(\mathrm{R}), \mathrm{IC}(\mathrm{bi}), \mathrm{PC}(\mathrm{bi}), \mathrm{TH}(\mathrm{bi})\end{array}$ & ref. 130 \\
\hline $\mathrm{AD}$ & $* \mathrm{fMRI}$ & Allergen - skin prick (VAC) & Left forearm (NLS) & $\begin{array}{l}\text { alC }(R) \downarrow, N A c(R) \downarrow, \text { putamen }(R) \downarrow, \text { globus pallidus }(R) \downarrow \text {, } \\
\text { caudate }(R) \downarrow\end{array}$ & ref. 151 \\
\hline AD & $* * \mathrm{fMRI}$ & Allergen - skin prick (VAC) & Left forearm (NLS) & $\begin{array}{l}\mathrm{MFG}(\mathrm{R}) \downarrow, \mathrm{PMC}(\mathrm{R}) \downarrow, \mathrm{M} 1(\mathrm{bi}) \downarrow, \mathrm{S} 1(\mathrm{bi}) \downarrow, \mathrm{S} 2(\mathrm{R}) \downarrow, \\
\mathrm{PCC}(\mathrm{L}) \downarrow\end{array}$ & ref. 151 \\
\hline
\end{tabular}

Activity changes in brain regions during suppression of itch transmission by cold block, scratching (active scratching by subjects or passive scratching by experimenters), butorphanol (a mixed action opioid), or acupuncture ( $R$, right hemisphere; $L$, left hemisphere; bi, both hemispheres). Unless otherwise indicated with $(\downarrow)$, all regions were activated during itch suppression. Brain imaging was performed following a VAC application to the itchy skin when the sensation of itch was either increasing* or at peak**. dIPFC, dorsolateral prefrontal cortex; dmPFC, dorsal part of medial prefrontal cortex; vmPFC, ventral part of medial prefrontal cortex; IPFC, lateral prefrontal cortex; vIPFC, ventral lateral prefrontal cortex; OFC, orbitofrontal cortex; MFG, middle frontal gyrus; MFC, medial frontal cortex; LFC, lateral frontal cortex; SMA, supplementary motor area; PMC, premotor cortex; M1, primary motor cortex; S1, primary somatosensory cortex; S2, secondary somatosensory cortex; ACC, anterior cingulate cortex; preACC, pregenual anterior cingulate cortex; subACC, subgenual anterior cingulate cortex; MCC, midcingulate cortex; PCC, posterior cingulate cortex; dPCC, dorsal posterior cingulate cortex; vPCC, ventral posterior cingulate cortex; IC, insular cortex; alC, anterior insular cortex; pIC, posterior insular cortex; NAc, nucleus accumbens; PC, parietal cortex; BG, basal ganglia; TH, thalamus; VTA, ventral tegmental area; PAG periaqueductal gray; $A D$, atopic dermatitis; ESRD, end-stage renal disease; NLS, nonlesional skin; VAC, verum acupuncture. 
activation in the thalamus as compared to histamine, as well as in other regions such as the IC, claustrum, globus pallidum, and putamen, consistent with the finding that cowhageresponsive STT neurons in nonhuman primates innervate larger areas within the thalamus than do histamine-responsive STT neurons $(81,113)$. Overall, both the pruritogens activate mostly overlapping regions. The S1 and S2 are specialized for receiving sensory input and are thought to participate in processing the sensory-discriminative aspect of itch. Since activity in the S1 is positively correlated with the intensity of an itch stimulus, this region is speculated to play an important role in interpreting the intensity of stimuli (105). Several studies report activation of the $\mathrm{S} 2$, but its role in itch is unclear (106, 111, 113, 114).

The IC is known to mediate the integration of autonomic, visceral, and limbic functions (115). It is connected to many other regions in the brain, including the cingulate gyrus, frontal, parietal, and temporal lobes, as well as subcortical structures such as the thalamus, amygdala, and brainstem $(116,117)$. Previous studies have shown that the IC can be roughly divided into several subregions with unique connectivity and functional features (118). The anterior agranular insular cortex (alC) is connected mainly to other cortical areas and plays a role in creating awareness of bodily states by integrating autonomic and interoceptive information, whereas the posterior granular part $(\mathrm{plC})$ receives nociceptive inputs from the primary afferents via the brainstem and thalamic nuclei to mediate pain processing $(115,119,120)$. It has been shown that itch activates both the alC and plC (107, 112). The activity in the alC is positively correlated with the unpleasant sensation of itch, while the activity of the $\mathrm{plC}$ is correlated with the intensity of the itch stimulus (105-107, 111-113). In ESRD patients with chronic itch, bilateral activation of the IC is observed even in the absence of pruritogen stimulation (114).

The cingulate cortex is one of critical brain regions contributing to the processing of the affective component of pain (121). For example, the anterior cingulate cortex (ACC) is activated upon anticipation or response to acute noxious stimulus or during chronic pain (122). Consistently, surgical damage to the cingulate cortex in humans decreases the affective response to noxious stimuli, while leaving intact the ability to localize the unpleasant stimuli $(121,123)$. The ACC is also activated by itch stimuli, mainly in its dorsal part (dACC) as well as in the anterior part of the midcingulate cortex (aMCC) (105-107, 110-114, 124). Since electrical stimulation of the MCC evokes the motivation to act, the dACC/aMCC appears to be associated with recognizing itch stimuli and preparing motor behavior (105, 107, 110-112, $125,126)$. Many studies have reported activation of other motor-related regions, including the supplementary motor area, premotor cortex, primary motor cortex, and cerebellum (105-107, 110-114, 124, 126, 127). These regions may play a role in recognizing the location of itch stimuli as well as organizing and executing motor responses such as scratching (105-107, 110-114, 124, 126, 127). Like the S1, activity in these regions is correlated with the intensity of the itch stimulus $(105,110)$. Interestingly, scratching the itchy skin also elicits activation of S1, S2, cingulate cortex, supplementary motor area, premotor cortex, primary motor cortex, and cerebellum. The activity is higher when scratching provokes pleasure than when it does not (128-130).

In rodents, the majority $(\sim 80 \%)$ of projection neurons in the superficial dorsal horn of the spinal cord innervate the PB, which is connected to the amygdala and hypothalamus and also to the IC (131). As described above, in vivo single-unit recordings in mice have identified pruriceptive neurons in the spinal cord and $\mathrm{V}_{\mathrm{C}}$ that project to $\mathrm{PB}$, implicating the spino-parabrachio-amygdaloid pathway in itch processing (132-134). Brain imaging studies, however, have failed to detect activity changes in the PB, probably because most of the projection neurons in the spinal cord in humans send their axons to the thalamus rather than the PB.

The amygdala is also one of the key cerebral structures participating in the sensation, expression, and modulation of pain $(133,134)$. In particular, the central nucleus of the amygdala (CeA) is considered the output nucleus of the amygdala and integrates nociceptive information from the cerebral cortex and thalamus as well as nociceptive inputs from the PB (135). A recent study has shown that inhibition of $\mathrm{GABA}_{\mathrm{A}}$ receptors by bilateral microinjection of bicuculline into the rat CeA dramatically increases scratching behavior in acute and chronic itch models, suggesting a role for inhibitory mechanisms in the CeA in itch modulation (136). Although the amygdala appears to be involved in itch processing, its role is still unclear, based on its activation in response to a combinatorial application of histamine and cowhage in one study but inactivated by individual treatment in another study $(106,113,137)$.

It has been reported that reversible cold-block or complete transection of the upper cervical spinal cord causes a $30-50 \%$ reduction in the inhibition of ongoing spontaneous firing of the dorsal horn neurons caused by scratching in a mouse model of chronic dry itchy skin, indicating that supraspinal mechanisms are partially involved in itch inhibition by scratching (138). Indeed, mosquito allergy-elicited biting behavior is inhibited by an intrathecal $\alpha(2)$-adrenoceptor antagonist but increased by the catecholaminergic neurotoxin 6-hydroxydopamine and the $\alpha$-adrenoceptor antagonist, indicating that the descending noradrenergic system tonically inhibits itch signaling in the spinal cord (139). Conversely, serotonergic neurons in the rostral ventromedial medulla appear to control itch transmission in the dorsal horn of spinal cord by facilitating GRP-mediated signaling (140). On the other hand, electrical stimulation of PAG inhibits the spiking responses of STT neurons activated by subcutaneous histamine (59). A human PET study has demonstrated that application of a painfully cold stimulus to histamine-evoked itch increases 
activity in the PAG, suggesting the possibility of a descending inhibitory mechanism of itch in the PAG (110). PAG was activated in response to scratching induced by cowhageevoked itch in one study but inactivated in another study (129, 141). Thus, the role of PAG in itch suppression is still disconcerted, and further investigation is necessitated.

\section{CONCLUDING REMARKS}

Compared to the extensive research on pain, itch has received relatively less attention until recently. However, our knowledge about the molecular and neuronal circuit mechanisms of itch detection in the skin and itch transmission within the spinal cord and $V_{c}$ has greatly expanded during the past decade. Identification of itch-specific receptors and neurotransmitters has provided important insights for development of novel therapeutic strategies that selectively target itch-mediating neurons.

Unfortunately, our current knowledge on the supraspinal processing of itch is limited and relies mainly on a small number of brain imaging studies. The reported studies have revealed that cutaneous pruritogen application activates brain regions involved in somatosensory, limbic, and motor-related functions, such as S1, the thalamus, ACC, IC, supplementary motor area, primary motor cortex, and cerebellum. Since the same brain regions are also activated by noxious stimuli, it is puzzling to note as how itch is distinguished from pain in the brain. Given their distinct sensations and different behavioral responses (scratching vs. withdrawal), there should be a mechanism by which these two sensory modalities are differentiated. One possibility is that a single population mediates both itch and pain, using distinct patterns of neuronal activation, spike timing, or other mechanisms. Another possibility is that the brain regions contain two intermingled or closely adjacent subpopulations that are each specialized for either itch or pain, but cannot be detected in brain imaging studies because of limited spatial resolution. Thus, it is essential to study itch in the brain using molecular genetic approaches to identify itch-mediating brain regions at the level of neuronal circuits and to decipher the neuronal circuit mechanism underlying the interrelationship between itch and pain. A combinatorial approach of the advanced techniques to reveal neuronal circuits, including in vivo imaging such as multi-photon microscopy and microendoscopy, functional manipulation tools such as optogenetics and chemogenetics, and population-specific neuronal tracing methods based on pseudorabies and herpes virus, will help us to achieve these goals (142-147).

\section{ACKNOWLEDGEMENTS}

This work was supported by the National Research Foundation of Korea (NRF) grant funded by the Korea government (MEST Grant NRF-2016M3C7A1904148), the Korea Brain Research
Institute basic research program funded by the Ministry of Science, ICT and Future Planning (No. 2231-415), and DGIST MIREBraiN Program of the Ministry of Science, ICT and Future Planning (2015080004).

\section{REFERENCES}

1. Ikoma A, Steinhoff $M$, Ständer S, Yosipovitch $G$ and Schmelz M (2006) The neurobiology of itch. Nat Rev Neurosci 7, 535-547

2. Yosipovitch G, Greaves MW, Fleischer Jr AB and McGlone $F$ (2004) Itch: basic mechanisms and therapy, CRC Press/Taylor \& Francis, Boca Raton, Florida, USA

3. Misery L and Ständer S (2010) Pruritus, Springer, New York, USA

4. Williams HC (2000) Epidemiology of atopic dermatitis. Clin Exp Dermatol 25, 522-529

5. Silverberg JI, Nelson DB and Yosipovitch G (2016) Addressing treatment challenges in atopic dermatitis with novel topical therapies. J Dermatolog Treat 11, 1-9

6. Beauregard S and Gilchrest BA (1987) A survey of skin problems and skin care regimens in the elderly. Arch Dermatol 123, 1638-1643

7. Mnyika K and Kihamia C (1991) Chloroquine-induced pruritus: its impact on chloroquine utilization in malaria control in Dar es Salaam. J Trop Med Hyg 94, 27-31

8. Sowunmi A, Fehintola F, Adedeji A et al (2000) Comparative efficacy of chloroquine plus chlorpheniramine alone and in a sequential combination with sulfadoxine-pyrimethamine, for the treatment of acute, uncomplicated, falciparum malaria in children. Ann Trop Med and Parasitol 94, 209-217

9. LaMotte RH, Dong X and Ringkamp M (2014) Sensory neurons and circuits mediating itch. Nat Rev Neurosci 15, 19-31

10. Bautista DM, Wilson SR and Hoon MA (2014) Why we scratch an itch: the molecules, cells and circuits of itch. Nat Neurosci 17, 175-182

11. Akiyama T and Carstens E (2013) Neural processing of itch. Neuroscience 250, 697-714

12. Ständer S, Steinhoff $M$, Schmelz M, Weisshaar E, Metze D and Luger T (2003) Neurophysiology of pruritus: cutaneous elicitation of itch. Arch Dermatol 139, 1463-1470

13. Rowley DA and Benditt EP (1956) 5-Hydroxytryptamine and histamine as mediators of the vascular injury produced by agents which damage mast cells in rats. J Exp Med 103, 399-412

14. Simone DA, Ngeow JY, Whitehouse J, Becerra-Cabal L, Putterman GJ and Lamotte RH (1987) The magnitude and duration of itch produced by intracutaneous injections of histamine. Somatosens Res 5, 81-92

15. Magerl W, Westerman RA, Möhner B and Handwerker HO (1990) Properties of transdermal histamine iontophoresis: differential effects of season, gender, and body region. J Invest Dermatol 94, 347-352

16. Bell J, McQueen D and Rees J (2004) Involvement of histamine $\mathrm{H} 4$ and $\mathrm{H} 1$ receptors in scratching induced by histamine receptor agonists in BalbC mice. $\mathrm{Br}$ J 
Pharmacol 142, 374-380

17. Han SK, Mancino V and Simon MI (2006) Phospholipase C $\beta 3$ mediates the scratching response activated by the histamine $\mathrm{H} 1$ receptor on $\mathrm{C}$-fiber nociceptive neurons. Neuron 52, 691-703

18. Shim WS and Oh $\cup$ (2008) Histamine-induced itch and its relationship with pain. Mol Pain 4, 29

19. Strasser A, Wittmann HJ, Buschauer A, Schneider EH and Seifert R (2013) Species-dependent activities of G-protein-coupled receptor ligands: lessons from histamine receptor orthologs. Trends Pharmacol Sci 34, 13-32

20. Shim WS, Tak MH, Lee MH et al (2007) TRPV1 mediates histamine-induced itching via the activation of phospholipase A2 and 12-lipoxygenase. J Neurosci 27, 2331-2337

21. Kim BM, Lee SH, Shim WS and Oh U (2004) Histamineinduced $\mathrm{Ca}^{2+}$ influx via the PLA 2/lipoxygenase/TRPV1 pathway in rat sensory neurons. Neurosci Lett 361, 159-162

22. Imamachi N, Park $\mathrm{GH}$, Lee $\mathrm{H}$ et al (2009) TRPV1expressing primary afferents generate behavioral responses to pruritogens via multiple mechanisms. Proc Natl Acad Sci U S A 106, 11330-11335

23. Shelley WB and Arthur RP (1955) Mucunain, the active pruritogenic proteinase of cowhage. Science 122, 469-470

24. Tuckett RP and Wei JY (1987) Response to an itch-producing substance in cat. I. Cutaneous receptor populations with myelinated axons. Brain Res 413, 87-94

25. Johanek LM, Meyer RA, Hartke $T$ et al (2007) Psychophysical and physiological evidence for parallel afferent pathways mediating the sensation of itch. J Neurosci 27, 7490-7497

26. Namer B, Carr R, Johanek LM, Schmelz M, Handwerker $\mathrm{HO}$ and Ringkamp M (2008) Separate peripheral pathways for pruritus in man. J Neurophysiol 100, 2062-2069

27. Johanek LM, Meyer RA, Friedman RM et al (2008) A role for polymodal C-fiber afferents in nonhistaminergic itch. Neurosci 28, 7659-7669

28. Sikand P, Shimada SG, Green BG and LaMotte RH (2009) Similar itch and nociceptive sensations evoked by punctate cutaneous application of capsaicin, histamine and cowhage. Pain 144, 66-75

29. Ringkamp M, Schepers RJ, Shimada SG et al (2011) A role for nociceptive, myelinated nerve fibers in itch sensation. J Neurosci 31, 14841-14849

30. Ma C, Nie H, Gu Q, Sikand P and LaMotte RH (2012) In vivo responses of cutaneous $\mathrm{C}$-mechanosensitive neurons in mouse to punctate chemical stimuli that elicit itch and nociceptive sensations in humans. J Neurophysiol 107, 357-363

31. Shelley WB and Arthur RP (1955) Studies on cowhage (Mucuna pruriens) and its pruritogenic proteinase, mucunain. AMA Arch Derm 72, 399-406

32. Reddy VB, luga AO, Shimada SG, LaMotte RH and Lerner EA (2008) Cowhage-evoked itch is mediated by a novel cysteine protease: a ligand of protease-activated receptors. J Neurosci 28, 4331-4335

33. Nystedt S, Emilsson K, Wahlestedt C and Sundelin J (1994) Molecular cloning of a potential proteinase activated receptor. Proc Natl Acad Sci U S A 91, 9208-9212

34. Shimada SG, Shimada KA and Collins JG (2006) Scratching behavior in mice induced by the proteinaseactivated receptor-2 agonist, SLIGRL-NH2. Eur J Pharmacol $530,281-283$

35. Steinhoff M, Neisius U, Ikoma A et al (2003) Proteinaseactivated receptor-2 mediates itch: a novel pathway for pruritus in human skin. J Neurosci 23, 6176-6180

36. Liu Q and Dong X (2015) The role of the Mrgpr receptor family in itch; in Pharmacology of Itch. Handb Exp Pharmacol 226, 71-88

37. Han L, Ma C, Liu Q et al (2013) A subpopulation of nociceptors specifically linked to itch. Nat Neurosci 16, 174-182

38. Liu Q, Tang Z, Surdenikova L et al (2009) Sensory neuron-specific GPCR Mrgprs are itch receptors mediating chloroquine-induced pruritus. Cell 139, 1353-1365

39. Lembo PM, Grazzini E, Groblewski T et al (2002) Proenkephalin A gene products activate a new family of sensory neuron-specific GPCRs. Nat Neurosci 5, 201-209

40. Sikand P, Dong X and LaMotte RH (2011) BAM8-22 peptide produces itch and nociceptive sensations in humans independent of histamine release. J Neurosci 31, 7563-7567

41. Liu Q, Sikand $P, M a C$ et al (2012) Mechanisms of itch evoked by $\beta$-alanine. J Neurosci 32, 14532-14537

42. Liu Q, Weng $\mathrm{H}-J$, Patel $\mathrm{KN}$ et al (2011) The distinct roles of two GPCRs, MrgprC11 and PAR2, in itch and hyperalgesia. Sci Signal 4, ra45

43. Reddy VB, Sun S, Azimi E, Elmariah SB, Dong X and Lerner EA (2015) Redefining the concept of proteaseactivated receptors: cathepsin $\mathrm{S}$ evokes itch via activation of Mrgprs. Nat Commun 6, 7864

44. Kuraishi Y, Nagasawa T, Hayashi K and Satoh M (1995) Scratching behavior induced by pruritogenic but not algesiogenic agents in mice. Euro J Pharmacol 275, 229-233

45. Shinohara T, Harada M, Ogi K et al (2004) Identification of a $\mathrm{G}$ protein-coupled receptor specifically responsive to $\beta$-alanine. J Biol Chem 279, 23559-23564

46. Dong X, Han S-k, Zylka MJ, Simon MI and Anderson DJ (2001) A diverse family of GPCRs expressed in specific subsets of nociceptive sensory neurons. Cell 106, 619-632

47. Zylka MJ, Dong X, Southwell AL and Anderson DJ (2003) Atypical expansion in mice of the sensory neuron-specific Mrg G protein-coupled receptor family. Proc Natl Acad Sci U S A 100, 10043-10048

48. Wilson S and Bautista D (2013) Itching for relief. Nat Neurosci 16, 775-777

49. Story GM, Peier AM, Reeve AJ et al (2003) ANKTM1, a TRP-like channel expressed in nociceptive neurons, is activated by cold temperatures. Cell 112, 819-829

50. Ferreira S, Romitelli M and De Nucci G (1989) 
Endothelin-1 participation in overt and inflammatory pain. J Cardiovasc Pharmacol 13 Suppl 5, S220-222

51. Katugampola R, Church MK and Clough GF (2000) The neurogenic vasodilator response to endothelin-1: a study in human skin in vivo. Exp Physiol 85, 839-846

52. Gomes LO, Hara DB and Rae GA (2012) Endothelin-1 induces itch and pain in the mouse cheek model. Life Sci 91, 628-633

53. Andoh T, Yoshida T, Lee J-B and Kuraishi $Y$ (2012) Cathepsin $\mathrm{E}$ induces itch-related response through the production of endothelin-1 in mice. Eur J Pharmacol 686, 16-21

54. Akiyama T, Carstens MI and Carstens E (2010) Facial injections of pruritogens and algogens excite partly overlapping populations of primary and second-order trigeminal neurons in mice. J Neurophysiol 104, 2442-2450

55. Yamaguchi T, Nagasawa $T$, Satoh $M$ and Kuraishi $Y$ (1999) Itch-associated response induced by intradermal serotonin through 5 -HT 2 receptors in mice. Neurosci Res 35, 77-83

56. Thomsen JS, Petersen M, Benfeldt $E$, Jensen $S$ and Serup $J$ (2001) Scratch induction in the rat by intradermal serotonin: a model for pruritus. Acta Derm Venereol 81, 250-254

57. Jinks SL and Carstens E (2002) Responses of superficial dorsal horn neurons to intradermal serotonin and other irritants: comparison with scratching behavior. J Neurophysiol 87, 1280-1289

58. Nojima $\mathrm{H}$ and Carstens E (2003) 5-Hydroxytryptamine (5-HT) 2 receptor involvement in acute 5-HT-evoked scratching but not in allergic pruritus induced by dinitrofluorobenzene in rats. J Pharmacol Exp Ther 306, 245-252

59. Carstens E (1997) Responses of rat spinal dorsal horn neurons to intracutaneous microinjection of histamine, capsaicin, and other irritants. J Neurophysiol 77, 2499-2514

60. Davidson S, Zhang X, Yoon $\mathrm{CH}$, Khasabov SG, Simone DA and Giesler GJ, Jr. (2007) The itch-producing agents histamine and cowhage activate separate populations of primate spinothalamic tract neurons. J Neurosci 27, 10007-10014

61. Simone DA, Zhang X, Li J et al (2004) Comparison of responses of primate spinothalamic tract neurons to pruritic and algogenic stimuli. J Neurophysiol 91, 213-222

62. Schmelz $M$, Schmidt $R$, Weidner $C$, Hilliges $M$, Torebjörk H and Handwerker HO (2003) Chemical response pattern of different classes of C-nociceptors to pruritogens and algogens. J Neurophysiol 89, 2441-2448

63. Schmelz M, Schmidt R, Bickel A, Handwerker $\mathrm{HO}$ and Torebjork HE (1997) Specific C-receptors for itch in human skin. J Neurosci 17, 8003-8008

64. LaMotte RH, Shimada SG, Green BG and Zelterman D (2009) Pruritic and nociceptive sensations and dysesthesias from a spicule of cowhage. J Neurophysiol $101,1430-1443$

65. Klein A, Carstens MI and Carstens E (2011) Facial injections of pruritogens or algogens elicit distinct behavior responses in rats and excite overlapping populations of primary sensory and trigeminal subnucleus caudalis neurons. J Neurophysiol 106, 1078-1088

66. Nicolson T, Bevan S and Richards C (2002) Characterisation of the calcium responses to histamine in capsaicinsensitive and capsaicin-insensitive sensory neurones. Neuroscience 110, 329-338

67. Amadesi S, Nie J, Vergnolle N et al (2004) Proteaseactivated receptor 2 sensitizes the capsaicin receptor transient receptor potential vanilloid receptor 1 to induce hyperalgesia. J Neurosci 24, 4300-4312

68. Spike R, Puskar Z, Andrew D and Todd A (2003) A quantitative and morphological study of projection neurons in lamina I of the rat lumbar spinal cord. Eur J Neurosci 18, 2433-2448

69. Sun YG and Chen ZF (2007) A gastrin-releasing peptide receptor mediates the itch sensation in the spinal cord. Nature 448, 700-703

70. Fleming MS, Ramos D, Han SB, Zhao J, Son Y-J and Luo W (2012) The majority of dorsal spinal cord gastrin releasing peptide is synthesized locally whereas neuromedin B is highly expressed in pain-and itchsensing somatosensory neurons. Mol Pain 8, 52

71. Mishra SK and Hoon MA (2013) The cells and circuitry for itch responses in mice. Science 340, 968-971

72. Liu XY, Wan L, Huo FQ et al (2014) B-type natriuretic peptide is neither itch-specific nor functions upstream of the GRP-GRPR signaling pathway. Mol Pain 10, 4

73. McDonald T, Jörnvall H, Nilsson G et al (1979) Characterization of a gastrin releasing peptide from porcine non-antral gastric tissue. Biochem Biophys Res Commun 90, 227-233

74. Andoh T, Kuwazono T, Lee J-B and Kuraishi Y (2011) Gastrin-releasing peptide induces itch-related responses through mast cell degranulation in mice. Peptides 32, 2098-2103

75. Sukhtankar DD and Ko MC (2013) Physiological function of gastrin-releasing peptide and neuromedin B receptors in regulating itch scratching behavior in the spinal cord of mice. PLoS One 8, e67422

76. Sun YG, Zhao ZQ, Meng XL, Yin J, Liu XY and Chen ZF (2009) Cellular basis of itch sensation. Science 325, 1531-1534

77. Wang X, Zhang J, Eberhart D et al (2013) Excitatory superficial dorsal horn interneurons are functionally heterogeneous and required for the full behavioral expression of pain and itch. Neuron 78, 312-324

78. Price DD, Hayes RL, Ruda M and Dubner R (1978) Spatial and temporal transformations of input to spinothalamic tract neurons and their relation to somatic sensations. J Neurophysiol 41, 933-947

79. Chudler EH, Foote WE and Poletti CE (1991) Responses of cat C 1 spinal cord dorsal and ventral horn neurons to noxious and non-noxious stimulation of the head and face. Brain Res 555, 181-192

80. Dado RJ, Katter JT and Giesler G (1994) Spinothalamic and spinohypothalamic tract neurons in the cervical enlargement of rats. II. Responses to innocuous and noxious mechanical and thermal stimuli. J Neurophysiol 
71, 981-1002

81. Davidson S, Zhang X, Khasabov SG et al (2012) Pruriceptive spinothalamic tract neurons: physiological properties and projection targets in the primate. J Neurophysiol 108, 1711-1723

82. Akiyama T, Merrill AW, Carstens $\mathrm{Ml}$ and Carstens E (2009) Activation of superficial dorsal horn neurons in the mouse by a PAR-2 agonist and 5-HT: potential role in itch. J Neurosci 29, 6691-6699

83. Akiyama T, Carstens MI and Carstens E (2009) Excitation of mouse superficial dorsal horn neurons by histamine and/or PAR-2 agonist: potential role in itch. J Neurophysiol 102, 2176-2183

84. Andrew D and Craig AD (2001) Spinothalamic lamina I neurons selectively sensitive to histamine: a central neural pathway for itch. Nat Neurosci 4, 72-77

85. Akiyama T, Curtis E, Nguyen T, Carstens $\mathrm{Ml}$ and Carstens E (2016) Anatomical evidence of pruriceptive trigeminothalamic and trigeminoparabrachial projection neurons in mice. J Comp Neurol 524, 244-256

86. Basbaum AI, Bautista DM, Scherrer G and Julius D (2009) Cellular and molecular mechanisms of pain. Cell 139, 267-284

87. Ballantyne JC, Loach $A B$ and Carr DB (1988) Itching after epidural and spinal opiates. Pain 33, 149-160

88. Thomas DA, Anton F, Kenshalo DR, Williams GM and Dubner R (1993) Noradrenergic and opioid systems interact to alter the detection of noxious thermal stimuli and facial scratching in monkeys. Pain 55, 63-70

89. Ständer S and Schmelz M (2006) Chronic itch and pain Similarities and differences. Eur J Pain 10, 473-478

90. Keele C (1970) Chemcial Causes of Pain and Itch. Annu Rev Med 21, 67-74

91. Sikand P, Shimada SG, Green BG and LaMotte RH (2011) Sensory responses to injection and punctate application of capsaicin and histamine to the skin. Pain $152,2485-2494$

92. Simone DA, Baumann TK and LaMotte RH (1989) Dose-dependent pain and mechanical hyperalgesia in humans after intradermal injection of capsaicin. Pain 38, 99-107

93. Green BG (1990) Spatial summation of chemical irritation and itch produced by topical application of capsaicin. Percept Psychophys 48, 12-18

94. Green BG and Shaffer GS (1993) The sensory response to capsaicin during repeated topical exposures: differential effects on sensations of itching and pungency. Pain 53, 323-334

95. Wang $\mathrm{H}$, Papoiu A, Coghill R, Patel T, Wang $\mathrm{N}$ and Yosipovitch G (2010) Ethnic differences in pain, itch and thermal detection in response to topical capsaicin: African Americans display a notably limited hyperalgesia and neurogenic inflammation. $\mathrm{Br} J$ Dermatol 162, 1023-1029

96. Moser HR and Giesler GJ (2014) Characterization of pruriceptive trigeminothalamic tract neurons in rats. J Neurophysiol 111, 1574-1589

97. Ikoma $\mathrm{A}$, Handwerker $\mathrm{H}$, Miyachi $\mathrm{Y}$ and Schmelz $\mathrm{M}$ (2005) Electrically evoked itch in humans. Pain 113, 148- 154
98. Tuckett RP (1982) Itch evoked by electrical stimulation of the skin. J Invest Dermatol 79, 368-373

99. Handwerker H, Forster C and Kirchhoff C (1991) Discharge patterns of human C-fibers induced by itching and burning stimuli. J Neurophysiol 66, 307-315

100. Lagerström MC, Rogoz K, Abrahamsen B et al (2010) VGLUT2-dependent sensory neurons in the TRPV1 population regulate pain and itch. Neuron 68, 529-542

101. Liu Y, Abdel Samad O, Zhang L et al (2010) VGLUT2-dependent glutamate release from nociceptors is required to sense pain and suppress itch. Neuron 68, 543-556

102. Roberson DP, Gudes S, Sprague JM et al (2013) Activity-dependent silencing reveals functionally distinct itch-generating sensory neurons. Nat Neurosci 16, 910-918

103. Ross SE, Mardinly AR, McCord AE et al (2010) Loss of inhibitory interneurons in the dorsal spinal cord and elevated itch in Bhlhb5 mutant mice. Neuron 65, 886-898

104. Braz JM, Juarez-Salinas D, Ross SE and Basbaum AI (2014) Transplant restoration of spinal cord inhibitory controls ameliorates neuropathic itch. J Clin Invest 124, 3612-3616

105. Drzezga A, Darsow U, Treede RD et al (2001) Central activation by histamine-induced itch: analogies to pain processing: a correlational analysis of O-15 $\mathrm{H}_{2} \mathrm{O}$ positron emission tomography studies. Pain 92, 295-305

106. Herde L, Forster C, Strupf M and Handwerker HO (2007) Itch induced by a novel method leads to limbic deactivations- A functional MRI study. J Neurophysiol 98, 2347-2356

107. Mochizuki H, Sadato N, Saito DN et al (2007) Neural correlates of perceptual difference between itching and pain: A human fMRI study. Neuroimage 36, 706-717

108. Dum RP, Levinthal DJ and Strick PL (2009) The spinothalamic system targets motor and sensory areas in the cerebral cortex of monkeys. J Neurosci 29, 14223-14235

109. Apkarian AV and Hodge CJ (1989) A dorsolateral spinothalamic tract in macaque monkey. Pain 37, 323-333

110. Mochizuki $H$, Tashiro $M$, Kano $M$, Sakurada $Y$, Itoh $M$ and Yanai K (2003) Imaging of central itch modulation in the human brain using positron emission tomography. Pain 105, 339-346

111. Mochizuki H, Inui K, Tanabe HC et al (2009) Time course of activity in itch-related brain regions: a combined MEG-fMRI study. J Neurophysiol 102, 2657-2666

112. Leknes SG, Bantick S, Willis CM, Wilkinson JD, Wise RG and Tracey I (2007) Itch and motivation to scratch: an investigation of the central and peripheral correlates of allergen- and histamine-induced itch in humans. J Neurophysiol 97, 415-422

113. Papoiu AD, Coghill RC, Kraft RA, Wang $H$ and Yosipovitch G (2012) A tale of two itches. Common features and notable differences in brain activation evoked by cowhage and histamine induced itch. Neuroimage 59, 3611-3623 
114. Papoiu AD, Emerson NM, Patel TS et al (2014) Voxel-based morphometry and arterial spin labeling fMRI reveal neuropathic and neuroplastic features of brain processing of itch in end-stage renal disease. Journal of Neurophysiology 112, 1729-1738

115. Craig AD (2009) How do you feel-now? the anterior insula and human awareness. Nat Rev Neurosci 10, 59-70

116. Saper CB (1982) Convergence of autonomic and limbic connections in the insular cortex of the rat. J Comp Neurol 210, 163-173

117. Allen GV, Saper CB, Hurley KM and Cechetto DF (1991) Organization of visceral and limbic connections in the insular cortex of the rat. J Comp Neurol 311, 1-16

118. Gu X, Hof PR, Friston KJ and Fan J (2013) Anterior insular cortex and emotional awareness. J Comp Neurol 521, 3371-3388

119. Coghill RC, Sang CN, Maisog JM and ladarola MJ (1999) Pain intensity processing within the human brain: a bilateral, distributed mechanism. J Neurophysiol 82, 1934-1943

120. Nieuwenhuys R (2012) The insular cortex: a review. Prog Brain Res 195, 123-163

121. Fuchs PN, Peng YB, Boyette-Davis JA and Uhelski ML (2014) The anterior cingulate cortex and pain processing. Front Integr Neurosci 8, 35

122. Iwata K, Kamo H, Ogawa A et al (2005) Anterior cingulate cortical neuronal activity during perception of noxious thermal stimuli in monkeys. J Neurophysiol 94, 1980-1991

123. Ballantine HT Jr, Cassidy WL, Flanagan NB and Marino R Jr (1967) Stereotaxic anterior cingulotomy for neuropsychiatric illness and intractable pain. J Neurosurg 26, 488-495

124. Ishiuji Y, Coghill RC, Patel TS, Oshiro Y, Kraft RA and Yosipovitch G (2009) Distinct patterns of brain activity evoked by histamine-induced itch reveal an association with itch intensity and disease severity in atopic dermatitis. Br J Dermatol 161, 1072-1080

125. Hsieh JC, Hagermark O, Stahle-Backdahl M et al (1994) Urge to scratch represented in the human cerebral cortex during itch. J Neurophysiol 72, 3004-3008

126. Darsow U, Drzezga A, Frisch M et al (2000) Processing of histamine-induced itch in the human cerebral cortex: a correlation analysis with dermal reactions. J Invest Dermatol 115, 1029-1033

127. Schneider G, Ständer S, Burgmer M, Driesch G, Heuft G and Weckesser M (2008) Significant differences in central imaging of histamine-induced itch between atopic dermatitis and healthy subjects. Eur J Pain 12, 834-841

128. Vierow V, Fukuoka M, Ikoma A, Dörfler A, Handwerker $\mathrm{HO}$ and Forster C (2009) Cerebral representation of the relief of itch by scratching. J Neurophysiol 102, 3216-3224

129. Papoiu AD, Nattkemper LA, Sanders KM et al (2013) Brain's reward circuits mediate itch relief. A functional MRI study of active scratching. PLoS One 8, e82389

130. Mochizuki H, Papoiu AD, Nattkemper LA et al (2015) Scratching induces overactivity in motor-related regions and reward system in chronic itch patients. J Invest Dermatol 135, 2814-2823

131. Braz J, Solorzano C, Wang X and Basbaum Al (2014) Transmitting pain and itch messages: a contemporary view of the spinal cord circuits that generate gate control. Neuron 82, 522-536

132. Gauriau C and Bernard JF (2002) Pain pathways and parabrachial circuits in the rat. Exp Physiol 87, 251-258

133. Carrasquillo $Y$ and Gereau RW 4th (2007) Activation of the extracellular signal-regulated kinase in the amygdala modulates pain perception. J Neurosci 27, 1543-1551

134. Neugebauer $V$ (2015) Amygdala pain mechanisms. Handb ExpPharmacol 227, 261-284

135. Veinante P, Yalcin I and Barrot M (2013) The amygdala between sensation and affect: a role in pain. J Mol Psychiatry 1,9

136. Chen L, Wang W, Tan T, Han H and Dong Z (2016) $\operatorname{GABA}(A)$ receptors in the central nucleus of the amygdala are involved in pain-and itch-related responses. J Pain 17, 181-189

137. Kleyn CE, McKie S, Ross A, Elliott R and Griffiths CE (2012) A temporal analysis of the central neural processing of itch. Br J Dermatol 166, 994-1001

138. Akiyama T, lodi Carstens M and Carstens E (2011) Transmitters and pathways mediating inhibition of spinal itch-signaling neurons by scratching and other counterstimuli. PLoS One 6, e22665

139. Gotoh $Y$, Omori $Y$, Andoh $T$ and Kuraishi $Y$ (2011) Tonic inhibition of allergic itch signaling by the descending noradrenergic system in mice. J Pharmacol Sci 115, 417-420

140. Zhao ZQ, Liu XY, Jeffry J et al (2014) Descending control of itch transmission by the serotonergic system via 5-HT1A-facilitated GRP-GRPR signaling. Neuron 84, 821-834

141. Mochizuki H, Papoiu AD and Yosipovitch G (2014) Itch: Mechanisms and Treatment. CRC Press/Taylor \& Francis, Boca Raton, Florida, USA

142. Svoboda K and Yasuda R (2006) Principles of two-photon excitation microscopy and its applications to neuroscience. Neuron 50, 823-839

143. Barretto RP and Schnitzer MJ (2012) In vivo microendoscopy of the hippocampus. Cold Spring Harb Protoc 2012, 1092-1099

144. Deisseroth K (2015) Optogenetics: 10 years of microbial opsins in neuroscience. Nat Neurosci 18, 1213-1225

145. Roth BL (2016) DREADDs for neuroscientists. Neuron $89,683-694$

146. Wickersham IR, Lyon DC, Barnard RJ et al (2007) Monosynaptic restriction of transsynaptic tracing from single, genetically targeted neurons. Neuron 53, 639-647

147. Lo L and Anderson DJ (2011) A Cre-dependent, anterograde transsynaptic viral tracer for mapping output pathways of genetically marked neurons. Neuron 72, 938-950

148. Valet M, Pfab F, Sprenger T et al (2008) Cerebral processing of histamine-induced itch using short-term alternating temperature modulation - An FMRI study. J Invest Dermat 128, 426-433 
149. Pfab F, Valet $M$, Sprenger $T$ et al (2010) Temperature modulated histamine-itch in lesional and nonlesional skin in atopic eczema - a combined psychophysical and neuroimaging study. Allergy 65, 84-94

150. Papoiu AD, Kraft RA, Coghill RC and Yosipovitch G (2015) Butorphanol suppression of histamine itch is mediated by nucleus accumbens and septal nuclei: a pharmacological fMRI study. J Invest Dermatol 135, 560-568

151. Napadow V, Li A, Loggia ML et al (2014) The brain circuitry mediating antipruritic effects of acupuncture. Cereb Cortex 24, 873-882 